\title{
The clinical manifestations of celiac disease may present at any age: A rare case report
}

\author{
Nezih Pişkinpaşa ${ }^{1}$, Mehmet Emin Pişkinpaşa ${ }^{2}$, Haluk Özçelik ${ }^{3}$ \\ 1. Uskudar State Hospital, Department of Gastroenterology, İstanbul, Turkey. 2. İstanbul Education and Research \\ Hospital, Department of Internal Medicine, İstanbul, Turkey. 3. Uskudar State Hospital, Department of Internal Medicine, \\ İstanbul, Turkey
}

Correspondence: Nezih Pişkinpaşa. Address: Altunizade Konutları D Blok No 10, Koşuyolu, İstanbul, Turkey. Email: nezihpiskinpasa@hotmail.com

Received: July 4, 2015

DOI: $10.5430 /$ crim.v2n4p96

Online Published: November 10, 2015

\section{Abstract}

A case report of a 87-year-old woman developing celiac disease has been discussed. The patient complained of irregular bowel habit, abdominal pain and mild weight loss at the walk-in clinic. Having symptoms fulfilling the ROME III criteria, fibromyalgia and osteopenia were the co-existing syndromes. The laboratory findings showed signs of anemia. Positive serological tests and duodenal biopsies confirmed the diagnosis of celiac disease. She was treated with gluten-free diet. Accordingly her symptoms relieved and her findings improved.

\section{Keywords}

Celiac disease, Gluten, Fibromyalgia syndrome, Irritable bowel syndrome

\section{Introduction}

Celiac disease (CD) is an immune-based enteropathy developing gluten intolerance. In those patients gastrointestinal (GI) symptoms like diarrhea, malabsorption and weight loss may occur. The symptoms are related to the intake of grains containing gluten like wheat, barley and rye. CD is commonly diagnosed in connection with extraintestinal problems, even some patients have no GI complaints; or some of them are detected in screenings in accordance with their positive family history ${ }^{[1]}$. Celiac disease has been more common in children and young adults, but in recent years rates of CD increased in the elderly population. This is observed in published clinical trials from North America and Europe (for example, about $7 \%$ of CD-diagnosed patients were 60 years and older in a Birmingham series; similar results have been found in a Mayo clinic series of $4 \%$ ). Some trials from the United Kingdom showed that about $25 \%$ of the patients were diagnosed first time in their seventies. In the clinical studies from the United States, Sweden, Scotland, Ireland and Canada similar results were obtained $^{[2]}$. The case presented below is a 87-year-old female patient who has celiac disease.

\section{Case report}

An 87-year-old woman having symptoms like irregular bowel habit, abdominal pain and mild weight loss presented in the walk-in clinic. Her symptoms fulfilled the ROME III criteria. She appeared healthy and did not report any rectal bleeding. 
She could eat well. Fibromyalgia Syndrome (FMS) and osteopenia were also diagnosed in this patient. She was not using any medications or receiving any treatments at this time. The only remarkable feature in her family history was her mother who died of bowel cancer. After taking the medical history report and the physical examination, blood samples for haematological and biochemical tests were collected. High fever or signs of malabsorption were not found. The patient didn't have any abdominal mass or hepatomegaly. No signs of dermatitis or arthritis could be detected. Tests of thyroid function, erythrocyte sedimentation rate, leucocyte counts as well as occult blood investigation in stool didn't show any abnormalities. Only iron deficiency anemia was diagnosed. Colonoscopy was performed as the patient had weight loss and cancer positive family history. Findings in the colonoscopy were normal. Results of the serological tests for celiac disease as like transglutaminase and endomysial antibodies were positive. Six different duodenal biopsies taken during the upper gastrointestinal tract endoscopy proved the celiac disease (see the Figure). Pathological findings confirmed the serological tests. The patient was set on a gluten-free diet. Afterwards her ferritin level increased as well as microcytosis vanished and findings of anemia resolved. Her disturbed bowel functions improved and changed to a better pattern.

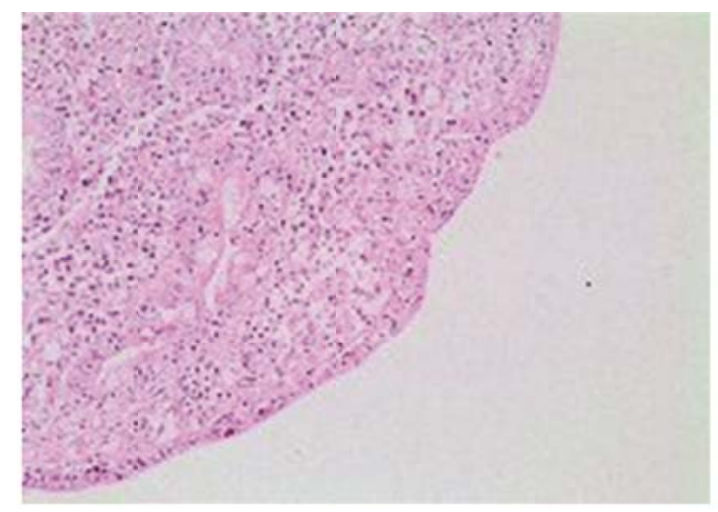

Figure. HE $3 \times 200$ : Total villous atrophy, intraepithelial lymphocytosis, increased lypmphoplasmacytic cells in lamina propria (Hematoksilen \& Eozin, ×200)

\section{Discussion}

Within last years the prevalence of CD is increasing; particularly due to the aging population ${ }^{[3]}$. As undiagnosed CD in this age group is recognised more frequently, the disease may be found in the elderly ${ }^{[2,4,5]}$. In United Kingdom the predicted prevalence of $\mathrm{CD}$ in individuals between the ages of 45 and 76 is approximately $1.2 \%$. About $20 \%$ of the new diagnosed CD cases are over 60 years of age. The disease has various clinical presentations in these older individuals. The patients may develop a silent disease, vague abdominal complaints or even anemia. Poor symptoms may also cause delays of the diagnosis ${ }^{[1]}$. We too experienced in our case of the 87-year-old patient had a delayed diagnosis of the disease. Celiac disease may resemble irritable bowel syndrome. According to a study in

which 105 patients were presumed to have IBS; 11.4\% of them actually had celiac disease. After confirming the diagnoses, these patients were treated for celiac disease rather than for IBS. Following the treatment their symptoms relieved.Another British study concluding about 300 patients having IBS were tested for specific antibodies. Results suggested that $22 \%$ of them had celiac disease. Later, intestinal biopsies confirmed unequivocally that $4.7 \%$ of these patients had celiac disease ${ }^{[6]}$. In our case, the patient fulfilled the ROME III criteria. She got gluten-free diet and her bowel habits changed close to a normal pattern.

In addition, the patient also had anemia according to test results. This haematologic disorder is the most frequent extraintestinal manifestation in celiac disease. Anemia was observed in nearly $39 \%$ of the patients. In a clinical study of Mandel et al. duodenal biopsies showed typical changes of celiac disease in $1.7 \%$ of the patients over 65 years of age having iron deficiency anemia. Iron deficiency anemia is frequently seen in the elderly (13.5\% of the patients over 70 years of age). But celiac patients have often subtle symptoms. Therefore, all cases having unexplained iron deficiency should be considered for the diagnosis of $\mathrm{CD}^{[7-9]}$.

In case of IBS-like symptoms the weight loss and anemia are alarming signs, and they are not explained by a functional disease (IBS) ${ }^{[11]}$. However, both findings were detected in the patient. Following the gluten-free diet her bowel habits turned to normal. If the mentioned clincal signs are found in patients having IBS celiac disease should also be considered.

$\mathrm{CD}$ is considered as a gluten-sensitive enteropathy. Its definite diagnosis is based on a positive small bowel biopsy and a proven response to a gluten-free diet. Serological test results commonly show the presentation of anti-tTg and others, e.g. endomysial antibodies (EMA). The presence of these antibodies has been reported in some studies. Due to a clinical and/or 
histological response to the gluten-free diet levels of serological markers decrease or disappear completely. Screening of the serological tests (IgA and IgG) support that they are not related to age in adults. However, sero-negative CD seems to be more common in the elderly. Even if the gluten consumption continues, the antibodies tTg and EMA spontaneously disappear in 49 and $45 \%$ of the cases. Despite that the procedural risk of endoscopy and biopsy seems somehow increased in the elderly, endoscopic biopsy remains vital as the "gold standard" for the diagnosis of CD in all age groups ${ }^{[11]}$. In our case the serological markers transglutaminase and endomysial antibody were found positive. The diagnosis of celiac disease has been confirmed by upper gastrointestinal endoscopy, duodenal biopsy and histopathology.

\section{Conclusion}

Celiac disease may occur at any age. It is more frequent in the 5th decade of life. About $70 \%$ of all adults having celiac disease are women. In our case the late occurrence of the disease may indicate the silent character of the CD as no clinical or histological pesentations have been observed for many years. Symptoms may be precipitated by stress, pregnancy, intestinal infections, abdominal surgery and increased gluten intake ${ }^{[10]}$. The patient probably experienced difficulties in compliance to her dietary restrictions because of her established dietary habits, financial problems and incompetency in getting the advised food products. As the diagnosis of the $\mathrm{CD}$ is not difficult in all age groups it is still underdiagnosed in the elderly. To avoid long delays in diagnosis and to prevent the occurrence of complications in elderly patients higher awareness of this condition is necessary.

\section{References}

[1] Freeman HJ, Chopra A, Clandinin MT, et al. Recent advances in celiac disease. World J Gastroenterol. 2011; 17(18): $2259-2272$.

[2] Freeman HJ. Adult celiac diseas in the elderly. World J Gastroenterol. 2008; 14(45): 6911-6914. http://dx.doi.org/10.3748/wjg.14.6911

[3] Vilppula A, Kaukinen K, Luostarinen L, et al. Increasing prevalence and high incidence of celiac disease in elderly people: a population-based study. BMC Gastroenterol. 2009; 9(1): 49.

[4] Thomson AB. Small intestinal disorders in the elderly. Best Pract. Res. Clin. Gastroenterol. 2009; 23(6): 861-874. http://dx.doi.org/10.1016/j.bpg.2009.10.009

[5] Rashtak S, Murray JA. Celiac disease in the elderly. Gastroenterol. Clin. North Am. 2009; 38(3): 433-446. PMid:19699406. http://dx.doi.org/ 10,1016/j.gtc.2009.06.005

[6] Kumar M, Rutecki GW. Atypical Celiac Disease: Could You Be Missing This Common Problem? Consultant. 2010; 50(3): 121-128.

[7] Bottaro G, Cataldo F, Rotolo N, et al. The clinical pattern of subclinical/silent coeliac disease: an analysis on 1026 consecutive cases. Am. J. Gastroenterol. 1999; 94(3): 691-696. PMid:10086653

[8] Mandal AK, Mehdi I, Munshi SK, et al. Value of routine duodenal biopsy in diagnosing coeliac disease in patients with iron deficiency anaemia. Postgraduate Medical Journal. 2004; 80(946).

[9] Fine KD. The prevalence of occult gastrointestinal bleeding in celiac sprue. N. Engl. J. Med. 1996; 334(18): $1163-1167$. PMid:8602182 http://dx.doi.org/10.1056/NEJM199605023341804

[10] Majewska A, Niemczyk S, Staszkow M, et al. Celiac disease manifest in the elderly. Polske Archiwum Medycyny Wewnetrznej. 2009; 119(4): 269-272. PMid:19413189

[11] Drossman DA. The functional gastrointestinal disorders and the Rome III process. Gastroenterology. 2006; 130(5): $1377-1390$. 